\title{
An example of a competency assessment portfolio, adapted for publication
}

Peter Robb

Peter Robb is a registered social worker in an Allied Health Adult Team. His iwi affiliations are Te Arawa/Ngati Whakaue/Ngati Te Roro O Te Rangi. He can be contacted by email at probb@xtra.co.nz.

\section{Introduction}

The competency assessment panel which assessed my competency assessment portfolio invited me to adapt it for publication in Social Work Review as a helpful contribution to social work practice. In adapting it I have reduced the word length and paid attention to matters of privacy and confidentiality. I am a registered social worker in an Allied Health Adult Team. I am of Te Arawa/Ngati Whakaue/Ngati Te Roro O Te Rangi descent with Scots/Irish/Spanish ancestry.

In describing the main focus of my current role and the key social work tasks and responsibilities involved, I reflect on how I keep my passion and motivation alive.

My current hours of work as a social worker are 80 hours per fortnight, and I work daily from 0730-1600. My role involves engaging with all Maori clients / patients admitted onto the eight wards that I cover; general medical and orthopaedics. There are also many instances when I am requested to engage with non-Maori clients. My personal view as a social worker is that we are all human beings, there is no place for differentiation by colour, creed or culture and so I meet with any client who needs a social worker. One of the key tasks required is to complete an initial psychosocial assessment. The assessment is an opportunity for the social worker to sit with the client in a conversation to collect information such as genogram/genealogy/whakapapa, social history, health history, social supports, accommodation, employment, financial (re)sources, education/ schools, transport, Enduring Power of Attorney and any other service(s) that may be involved in identifying the needs of the client(s). I see my primary role as a social worker as being to involve the client and their family at the highest level in participation, problem solving and decision-making. It starts from the very first meeting/engagement. I greet the client formally, introduce myself by name and as a social worker showing my ID and then explain my role. The client may ask questions about the help I may be able to provide and so starts the beginning of rapport, relationship building and achieving the ideal of a therapeutic relationship. This is the intended bonus and the initial psycho-social assessment is the vehicle that provides the opportunity. Of course it is not solely the assessment. It is also about active listening to a narrative which I believe creates a therapeutic milieu allowing the client to relax and trust the social worker to help them achieve their goals. It also allows the client to feel the benefit from having an important role to play in the whole process (identifying their needs, participating in a conversation, seeking from the social worker options and choices, and developing a care plan which, I believe, reflects their independence and sense of self worth. 
There is great satisfaction assisting clients in a hospital setting where they can be disturbed by what ails them medically. Providing information about resources available, services both intra DHB and in the community, providers who take up referrals for home help, all contribute to giving the client a sense of relief knowing that on discharge they will be supported to a level that will ensure their recovery is both sustained and enhanced. Sometimes I use interpreters for those clients and families where English is a second language. This ensures clients are not disadvantaged in getting what is needed for their care plan and making their discharge planning simple and easily understood. I also advocate for clients so their access to resources and services is not diminished, as is their right to question any aspect of the care plan without discrimination or penalty.

Other tasks will include, organising client access to kaumatua with a referral to Maori Services of the DHB, particularly for elderly Maori clients who wish to engage in korero te reo Maori, and to have karakia. This also includes the families of clients. An important role is supporting the family / whanau of clients when family meetings are convened. These are usually called by the Multidisciplinary Team (MDT), but not exclusively, as families can also seek the opportunity to be able to ask questions to clarify the diagnosis, treatment plans and the prognosis of their family member so they are able to understand what is happening. I am also involved in advising families who come from outside the DHB region of accommodation available to them - for Maori clients this is through Maori Services. There is accommodation on site that uses the model of a marae environment, which helps families feel comfortable, connected and close to their family member/client. It is also available to non-Maori families and reflects for me the Maori ethos of inclusion, manaaki and awhi. Other options for accommodation are facilitated through the Ministry of Health and/or other DHBs who provide the financial resources for family accommodation.

Another key task that I see as integral to my work is the effort I make to continually consult organisations involved with service users and update services which provide services and support for clients in hospital. This involves Mental Health services and key workers, home services both iwi and mainstream, community social workers et al. I am a firm believer in the right hand knowing what the left hand is doing and by attending to this task I am ensuring there is a collegial and collaborative relationship that works towards the client being fully supported both by the hospital and the community.

My motivation is drawn from my love of my role as a social worker. I pride myself on my professionalism, my ability to engage with and actively work on behalf of a wide range and variety of cultural groups/clients and their families. I bring to bear all of my efforts to facilitate resolutions for their needs. I believe I am an interface for clients for their social needs between their families and the DHB/hospital. My passion for my work also comes from my desire to see families (with the help of the social worker) realise their ability to find within themselves the answers to their problems and needs. Or as Benjamin Disraeli stated: 'The greatest good that you can do for another, is not just to show them your riches, but reveal to them their riches' (1804-1881).

\section{Supervision and supports (e.g. networks, systems, etc) I access and use in my professional work}

Supervision is a requirement of my employment with the DHB and is required under the rules of the ANZASW in meeting the criteria to maintain my Annual Practice Certificate and Registration with the SWRB. My supervision was fortnightly when I first started in my 
role, but with the agreement of my Practice Supervisor this has been reduced to monthly supervision. My supervision is a mix of formal and informal, it allows for open and honest discourse and provides the opportunity to explore practice, to analyse my practice, to assess the appropriateness of actions taken and identify professional learning options for my ongoing development as a social worker in allied health. My supports include my social work colleagues, where I am able to seek advice as and when I need.

Allied health social workers in the department in which I work meet fortnightly in a forum to discuss relevant matters pertaining to our roles. It also provides the opportunity to bring in outside services to present to the group what services they provide that may be used by clients. It is an opportunity for networking, and also for accessing the Professional Social Work Leader who regularly meets with all social workers and who plays an active advisory and support role around professional development needs. The DHB also provides professional training for supervision for the supervisee so that the supervisee can get the most out of their supervision. The ANZASW is another support for all social workers in New Zealand.

\section{A reflection on how my Continuing Professional Development has contributed to my devel- opment as a social worker}

My CPD has been a prime contributor to my development as a social worker. I have participated in and completed training courses relevant to the roles I have had, whether as a social worker or in other roles as a non-practising social worker. These roles have utilised my social work skills and knowledge e.g. FGC Coordinator both CP and YJ, Care Coordinator, Community Support Worker, Probation Officer and Mental Health Rehabilitation Therapist for clients whom I have worked with and provided my services in my career to date.

In-service training has been at the nexus of my drive and my focus to develop my social work skills. As a mental health key worker/social worker I participated on whatever courses were available that I felt could benefit my clients. Some of these included managing challenging behaviour, risk assessment, super user for HCC's computer system (where I provided in-service training for colleagues of many disciplines who had problems with the new system) and Dual Diagnosis / AOD where I learned motivational interviewing and how to bring this to my practice for clients who were experiencing problems.

For me it is important that in my development as a social worker I continually seek to improve by gaining more knowledge and skills. As a social worker with a DHB there are mandatory courses that I am required to complete to enhance my role, such as Family Violence/Partner \& Child abuse, Tikanga Best Practice, Working with Interpreters to name a few. These provide me with the requisite knowledge base that I need, particularly when I am on call and where (unfortunately) domestic violence referrals are many. Knowing how to deal with and manage clients in these situations has given me confidence and means I will become better in future engagements. This ongoing training and development will always be an integral and relevant ingredient to my roles. I believe I am a better social worker as a result of my continuing professional development, as I have intertwined my life experiences with what I have learned through the courses I have completed to bring about a holistic methodology to use in my practice. As my social work lecturers/tutors always said to me, do not compartmentalise yourself in your knowledge and practice skills, have as wide a base as possible. It allows you to work with a wide variety of clients. 


\section{Introducing referees}

The way I introduced my referees was considered a particularly helpful example of how to carry out this part of the written competency assessment. It is an aspect that is often overlooked, but it is, in fact, a very significant opportunity for the candidate to provide an example of good process.

\section{Colleague}

I have chosen a charge nurse as my colleague reference. I have worked with her in my capacity as one of the social workers on her ward. My tasks are to primarily engage with clients who identify themselves as Maori. As the charge nurse, she has seen how I have engaged my clients, and facilitated their needs identified through an initial psycho-social assessment. I have also assisted the nursing staff with clients who cause difficulties through threatening behaviour, obscene language and non-compliance with medication. The charge nurse identifies my strength in engaging these clients in a non-threatening, calm manner, seeking to de-escalate their anger and calling on them to address their behaviour so that their treatment can continue. She has called on me several times in this capacity and acknowledges my abilities with gratitude when I have resolved these situations. I have also made myself available to engage with non-Maori clients when my social work colleagues are not available and/or in cases of urgency. She knows that I have no problems moving between and engaging with both Maori and non-Maori clients and again calls upon my services regularly. I take the view that as a social worker all clients are important and if there is a need that I can fulfil then I am more than willing to provide my services.

\section{Client: The person or group who has received my professional services}

I have chosen $X X X$, as he can comment on my practice as a social worker who worked closely with him and his family from engagement to discharge. I got to know XXX over a 10-12 week period of stay in hospital. From our first meeting we developed a mutual relationship that was warm, cordial, respectful and meaningful. It gave both of us moments where we would talk about early childhood memories that each could identify with. Similarities in our upbringing as Maori and experiences that shaped and had influence in both our thinking and our lives brought with it a therapeutic value that XXX appreciated. He stated on many occasions how much he enjoyed our conversations. His wife likewise regularly sought me out when I was on the ward to say how much she appreciated the time and effort I took to spend with her husband. I believe I afforded XXX and his family the emotional, professional and cultural support that helped sustain them during a difficult and stressful time during his stay at the hospital. Just by being there for them daily, seeing him when he wanted to see me, and keeping the contact and communication with the family on a regular basis, provided a sense of inclusion, value and relief knowing that as his social worker they were able to trust my actions.

\section{Practice examples}

Having introduced the referees, I then include my practice examples to demonstrate how I adhere to the ANZASW Code of Ethics and Practice Standards in my work.

\section{Code of Ethics}

The ANZASW Code of Ethics provides clear guidelines for social workers. My commitment to the Code of Ethics is reflected in my practice and, to ensure my practice is ethical and 
in accordance with practice standards, I use my supervision in order to maintain this commitment. As a social worker who uses the Strengths Model, I am a firm believer that clients have the right to independence.

When I worked as a community support worker and also as a key worker/ social worker in mental health, I accepted there would be a level of dependence when I first engaged clients. My role then was to complete assessments which would have the client identify goals they wished to achieve, to identify supports and indicate whether family or others in their community could be called upon to help. I would then ask the client to timeframe this after working collaboratively with them in developing a plan, their plan that would see them move in a planned and managed way towards their goals.

As our relationship developed with trust and respect and we achieved a good rapport, my focus progressed to moving clients towards a level of inter-dependence over a period of 3-6 months. This would mean that when, as the social worker, I did something for the client, I would then encourage the client to do something for themselves. This helped build their confidence, their reliance on themselves and provided the opportunity for clients to know that they could make decisions and carry out tasks that they needed to do. The end goal to me as the social worker was to have the client achieve as high a level of independence as they felt comfortable with, knowing they can still get support if necessary but also knowing that their right to independent decision making is validated by their independence. In achieving independence, they realise they were no different from the rest of society.

My practice is non-discriminatory, and I have and will continue to work with a wide range of cultural groups regardless of their origins, religion, language, political beliefs or sexual orientation. I look at clients as human beings who are seeking help and my commitment to them is unwavering in that regard. At every step of my engagement with clients I continually reassess my practice during supervision and in my conversations with colleagues. I am always prepared to relate a situation that I have had some difficulties with to my colleagues to get a different perspective and to put those perspectives up against mine to see if I have considered all options, approaches and whether I can improve further. I am confident and strong enough to seek advice and counsel to address decisions that I have made that could have been made better and to change tack if needed.

\section{Demonstrating a commitment to Maori as tangata whenua}

How I demonstrate a commitment to Maori as tangata whenua in accordance with the ANZASW Code of Ethics and Te Tiriti O Waitangi.

I identify as a Maori and a social worker. I believe I have an inherent understanding and empathy with Maori in recognising them as tangata whenua. My practice, though based on the Strengths Model, also supports other concepts that I recognise: kotahitanga (together as one/partnership) kaitiakitanga (guardianship/protection) and tino rangatiratanga (independence/ autonomy).

The Maori arm of the DHB where I work provides policy advice and services for Maori health. The Chief Cultural Advisor provides guidance to the DHB for appropriate cultural practices that recognises the unique relationship of Maori under the Treaty of Waitangi. As a social worker working with Maori clients, I actively promote the use of practices enshrined in tikanga as a 
vehicle for best practice. I uphold these rights/rites at every opportunity, particularly when I see transgressions, e.g. staff sitting on tables, incorrect coloured pillow slips for different parts of the body, clients being taken for surgery and being wheeled out head first and not feet first. These are just some of a wide variety of aspects of tikanga that all staff are required to know about and adhere to. My active promotion of tikanga recognises the status of Maori as tangata whenua and the role social workers play in helping address issues of social justice. I believe that Maori must also play their part by accepting the need to show social responsibility.

The Treaty does underline a 'partnership' and so it is incumbent on both signatories to reflect that partnership by honouring their responsibilities and actively working towards achieving that goal. At the individual level the success of the work of social workers can be measured in positive outcomes for their clients and this can translate onto their whanau/hapu/iwi. Structural achievements can be evidenced in the implementation of tikanga recommended best practice policy which underpins a social perspective for Maori in a health setting.

\section{Appropriate and purposeful working relationships with clients}

Here I provide examples of how I develop appropriate and purposeful working relationships with clients, taking into account individual differences and the cultural and social context of the clients' situation.

I work with a wide range of cultural groups that have English as their second language, different religious beliefs, ages ranging from 17 to 90 , genders, different sexual orientation and those who may have a disability. I treat all clients equally, without bias but at the same time acknowledge their individual differences, their cultural and social contexts.

A charge nurse from one of the wards asked me to facilitate an urgent family meeting that involved an Indian family. The patient was due for discharge and the meeting (called for by the family) was to discuss community support services/needs for the client. An interpreter had been arranged for this. One family member was able to converse to some degree in English so my first contact with the family was through this family member and the interpreter. I formally introduced myself, I explained my role and showed my ID. Whilst having a three-way conversation was at times laboured, my purpose was to facilitate an outcome that met the client and family's needs. In this way, I ensured the client and their family were clear about treatment plans, discharge planning and support needs when they returned to their home and community.

I use the Strengths Model with almost all of my clients. I think clients and their families come to realise how they value this model as it brings out the resources they have within their family and their social context. This gives them purpose and a sense of usefulness for the resolution of their needs. Enabling clients to do things for themselves enhances and maximises the chances of success. Being honest and respectful at all times endorses their self worth. Talking with them rather than to them, making sure we all recognise that the social worker doesn't know everything about fulfilling their need and is not a miracle worker nurtures a collaborative relationship.

\section{Securing the participation of clients in the working relationship}

The Strengths Model offers me the best opportunity to engage with the client in actively securing their participation in all aspects of the working relationship. This extends from 
identification of needs in the initial psycho-social assessment and helping with problem solving if required, to developing a care plan that facilitates an integrated approach from all disciplines within the MDT and secures a discharge plan that the client (and their families) feel they have played an active role in deciding on.

I apply this approach to all clients, but for Maori clients I have called upon the services of kaumatua to incorporate tikanga for clients to provide a service that is responsive to their rights / rites and is an issue of principle, values and spirituality. It conveys 'as much a comment on process as it is on fixed attitudes or knowledge' (Durie, 2006, p. 23). Maori views on health include a holistic approach encompassing the elements of wairua, hinengaro, tinana and whanau among other concepts. Karakia is essential in protecting these concepts within a healthcare setting and offer every success in achieving a valued and respectful working relationship.

Just taking the time to sit and talk with clients is in itself a therapeutic intervention. Getting alongside them and opening up the discourse to cover all areas of their lives allows them to tell their stories.

Recently I had a husband and wife as clients on two separate wards. The wife was an oncology patient, the husband was in hospital for his non-compliance with medication for his diabetes. The husband was in a fragile state, suffering from loss of balance, shivers and general low wellbeing. He realised that not taking his medication was affecting his ability to care for his wife, for whom he had a carer role. When he had stabilised after the reintroduction of his insulin he was better able to converse with me. I discussed with him the need for and the importance of his medication to manage his diabetes. I stressed that the role he had as carer was predicated on his compliance. I acknowledged that the condition of his wife, whilst important, also meant his condition was important too. I talked with him one-on-one expressing empathy and aroha in a spirit of sharing and concern by getting through his sense of whakama, validating his fears and that he need not be ashamed. It was important to portray to him that he possessed the strength and wherewithal to overcome his challenges not just for himself but also for his wife. I encouraged him to accept the challenge, I reinforced this with positive affirmations of his abilities and that he could become the rock upon which his wife would depend. He became emotional during our conversations, but I began to notice a change in his attitude, his manner, his bearing, how he spoke and a look in his eyes and on his face. He had turned a corner with the realisation of what was really important. Later when I visited his wife, she related to me how much she had seen a 'change' in her husband and attributed this to my talking with him. I was complimented by her saying 'you have been the first social worker who has ever talked, just talked with my husband and he is now realising that he also needs to think about himself and his own needs, in order to provide the support, the base I need'. The wife was appreciative of my efforts and conveyed her thanks in her words and her emotions for the time I had taken to sit alongside/with her husband to help him realise what he needed to do. As a result of how I engaged with both clients, our working relationship became one of mutual respect, acceptance of what I had to offer and newfound realisation and understanding of what they were able to bring to resolving their needs. They were able to find the answer(s) within themselves and were confident they would rise to any future challenge(s). 


\section{Demonstrating my ability to work with people in a way that helps them to make their own decisions and to assist them in the achievement of their goals}

I believe in the right of clients and their families to participate in problem solving and making decisions that resolve their needs / goals. I recognise and acknowledge the right of clients to their independence and the right to make informed decisions for themselves. An example is with clients who are applying for a WINZ benefit. My role is to see that the client completes as much of the application as possible if they have never done so before (which is rare). In doing so my actions enable them to undertake, complete and achieve something for themselves. I am always there to provide some input, but I maintain a line that clients can make good decisions for themselves with good support.

This is also the case with clients who require accommodation. I provide an accommodation list of options, addresses, what is available and relevant costs. I arrange for clients to have access to a phone to canvas the options on the list after they identify two or three options they wish to follow up on. When the clients make their choice, they use the services of WINZ liaison to see what financial assistance could be provided by way of any advances so the client could secure the accommodation. I then fax the relevant information to the accommodation provider with the client's consent.

I believe that clients appreciate such opportunities and I am more than willing to walk a client through any process that sees them come out the other side of it with a new learned skill. I will do some things for clients but not everything and I am always careful to stress that boundary at the first engagement by saying,'I will help you but you will do the work.' This has always worked for me in my practice.

\section{My personal approach to social work practice}

\section{Personal attributes}

I am a mature, well-travelled, experienced social worker. I am comfortable with my use of self-disclosure which I feel contributes to developing a therapeutic relationship with my client(s) and their families. It shows my humanity that I feel they can identify with in terms of seeing that we all endure hardships or challenges and that no one is immune from them. I am resilient and therefore maintain my focus and efforts when caseloads are heavy and timeframes are tight and when, no matter what, the job still has to get done. My organisational skills which I learned and developed from my time in the Navy to the present day, affords me the capacity to undertake high caseloads, many with some complex needs and issues, without any difficulty.

I am a team player and therefore more than prepared to help and assist my colleagues should they request assistance or even when they do not, I make the offer regardless.

As a mature male I also feel that I provide a different perspective for the predominantly female team I work in. I am a hard worker who will take on any task asked of me. I am happy to ask for help when I feel I need it or ask the hard questions when need be. I am a grandfather and a husband with a wife who has been diagnosed with MS and feel I have become a stronger person as a result of having to consider the challenges of the unknown that lie ahead of us. But we do this together and it has given me an insight into the trials and tribulations some of us face every day; yet it also shows me that there will always be 
someone else worse off. Challenges are what life presents to us, how we respond to those challenges will define ourselves as human beings and the quality of our lives.

Particular strengths and challenges I face in my social work role

As a former serviceman (Navy), I bring to my work a sense of organisation, planning, an understanding of how a team can work effectively and a high level of resilience. I was taught in the Navy that no matter how hard the job, it still had to get done. It gave me the capability and capacity to plan my day ahead and this provided me with the ability to reschedule or juggle appointments when crises or clashes of agendas arose. I was a radio operator in the Navy and therefore I have a very good ability to speed type. In doing this there was no diminution from my core role of meeting with clients, assessing their needs and working towards facilitating them. There have been times when I was working in mental health with CMDHB in a community mental health centre where I was asked to be the typist for the morning meetings using a laptop with a projection facility. I was able to type as quickly as team members could speak. I was also adept with the HCC computer system used by the DHB. I became a super user, able to help colleagues with client care plans that were regularly audited for compliance.

My major challenge is ensuring I am working to the highest level I can in providing a service to my clients. I am always prepared to ask the question of myself, challenge myself in terms of my practice and my team members whether I have or could have done things better. I am a believer in the notion that we should challenge ourselves as social workers regularly and without fear. We are not miracle workers and sometimes we do not have all the answers, but we can always strive to do things better and with reflection and supervision we always work towards developing a higher standard of service.

\section{How I recognise my stress indicators and manage these to practise effectively}

Over the years I have learned how to identify when my stress levels are rising. One indicator I recognise is quietness. I have been able to manage this without much difficulty, and I have done this through regular exercise and adherence to a fitness regime that is disciplined and highly addictive. I am an avid gym person, six days per week, sometimes seven, with a 90 minute workout. I have a gym buddy and we motivate each other with laughter and application. I believe I have the ability to relax more. Being fit brings with it a sense of calm and confidence, self-assuredness and a sense of appreciation of one's physical appearance. I am able to work under tight timetables without feeling stressed. This allows me to take a measured approach to my work and practice. I am not flustered nor do I panic. My modus allows me to organise and plan my approach so that I am able to facilitate client needs expeditiously without a drop in the level of quality. One other important factor is having a life away from work which also helps me manage stress. When I leave work, I leave work behind me. I have a full and active life away from work with my family and friends. I never bring problems or issues to work that have nothing to do with work, I keep the two separate. It works very well.

\section{Theories/methods/tools I use in my practice.}

I use the Strengths Model in my practice, I have on some occasions used Te Whare Tapa Wha with both Maori and non-Maori clients, but my preference is the Strengths Model. I believe that the Strengths Model provides a good base to start with a client for facilitating participation, problem solving and decision making. I try to keep things simple, working 
at a speed and level the client is comfortable with. Attending to detail and always making sure that when I have scheduled a visit I keep it. My word is my word and clients appreciate my dedication. Key to my practice is how I engage the client (and their families) from the very beginning, formal at the start and then becoming less formal but still professional and friendly. My aim is to build a therapeutic relationship in the context of a hospital setting which can be difficult and brief, but all the same my experience is that I have been able to achieve good results using my approach regardless of the length of stay. Within this therapeutic relationship and treating clients as individuals who have strengths and resources and not someone who has an illness or medical condition, I validate their right to independence and a choice of lifestyle they desire.

\section{How I keep informed on matters of policy for my agency and nationally}

As a member of the Association I regularly read the notices that are emailed to me, e.g. Noticeboard and Social Work Review when sent out to members. The DHB Professional Advisor is a resource that social workers at the DHB can access for help and to be kept informed of policy matters within the DHB that relate to practice and other social work issues.

There are regular fortnightly business meetings lead by the Team Leader that cover a wide range of agenda items from professional development policy, operational policy, quality assurance and OSH considerations. Social workers also meet fortnightly to follow up on agenda items provided by in the team they feel important e.g. PSA matters, on-call issues, service providers and the changes in their services and the effect on the DHB and clients. The CEO of the DHB also sends out regular updates of DHB initiatives and policy development. The DHB also has a newsletter that provides a wide range of topics relevant to the whole DHB and includes policy matters.

\section{Networks I access for clients' wellbeing}

Clients will come with different needs, which determine what networks/resources I can access for their wellbeing. For Maori clients this will include DHB services (Maori), which give support to clients, and it also involves referrals for accommodation located on site for out-of-town families so they can be near their family member.

Examples for all clients include, the Cancer Society, Te Hononga, Whanau Ora, CADS, Counselling services, mental health centres/services, Taikura Trust, WINZ liaison, HNZ liaison, and home service providers, Iwi social services, all of whom provide a service for all clients when they are back in the community. I use as many services that are available to help to sustain and maintain clients' continued wellbeing and ideally keep them in their community. When referrals for home services / home help are submitted for clients who don't have family support, there is a discussion with the provider and/or in the case of the DHB the referral centre, about what the client needs and how best the service can meet that need.

Having colleagues who have worked in the team longer than me, I am able to ask for information/ resources they are aware of for my clients.

\section{Systems of accountability within the agency and how they meet my professional needs.}

I use supervision as an avenue for accountability in respect of my professional needs and practice. My practice supervisor is a resource and someone with whom I can discuss my practice, methods and models used and cultural approaches when working with clients, to ensure 
appropriateness and that I am working at a high level of professionalism. Supervision also provides a discussion around whether I have considered all options and whether there were opportunities for doing things better and is there any learning in my interactions and practice.

In tandem with this, my team leader is also someone whom I can engage to discuss my goals and objectives, get some guidance in relation to my professional development and the benefits that may be brought to the service in my area of work.

Both my practice supervisor and team leader have given me support to pursue targeted training and courses that will help meet my professional needs and to bring that learning to the service and in my practice and interactions with my clients.

\section{Examples of how I advocate at micro and macro levels to ensure systems are responsive to the needs of service users.}

As a social worker I aim to keep things simple, because it is complicated enough doing social work with a myriad of tasks and responsibilities attached to the role, especially when you are working with a wide variety of clients from differing backgrounds. So I believe if I keep it simple I am able to achieve more progress in terms of responding to client needs than I would otherwise. I am new to my current position and recognise the need to work towards ensuring systems are responsive to clients and service users. So I see the client as being at the micro level, and the macro level is their 'family/whanau'. My work is from the centre out, with the client at the centre. I try to raise the client's awareness of their needs, their responsibilities and how they can make changes in their lives with appropriate support and make decisions concerning themselves and their needs.

I provide information that can be accessed in the community and choices for the client to consider, and ensure that using the guidelines of Tikanga Best Practice supports a cultural response in terms of appropriate and culturally safe practice for Maori clients. At rapid round and MDT meetings I have the opportunity to advocate on behalf of the client and the family in terms of their needs. Families are as important in the process as the client. Maori service users/ clients come from a collective cultural base and this foundation is important if the social worker is to identify a wider range of resources from this base, which then can be used in the decision-making process and better reflects that what is better for the individual is also better for the whole.

\section{Using membership of the ANZASW to influence and reinforce competent practice}

I am proud to identify myself as a member of the ANZASW through all of my communication with other disciplines, clients and with other social work colleagues. I wear my 'ID badge and my APC' with honour. As a member I feel I have the professional support and backing of an organisation that actively promotes and advocates good social work practice, provides good forums for social workers to contribute feedback and to meet to discuss issues within their respective agencies. My links with other social workers can come from client needs. I regularly work with community social workers when referrals are made, as well as intra-agency social workers, e.g. community mental health centres, DHB community support services, older person health, CYFS / Starship, schools and NGOs to name a few. The Allied Health Adult Team I am attached to holds regular journal clubs where there is a round-table discussion and conversation on topics relevant to social work. This helps maintain a social work perspective covering a wide variety of topics and/or issues. 
I have also been a member of a competency panel. This is as an opportunity that reinforced my feelings of self worth and self esteem both as an individual and as a social worker by contributing back to the ANZASW some part of my work experience and knowledge. It was an experience that I thoroughly enjoyed.

\section{Conclusion}

This concludes what I can share of my competency assessment. I have tried to alter it as little as possible, but have had to shorten it where possible. For me, this has been a worthwhile process which reminds me of the need to be mindful of my professional activities and how I justify them, nurture them and even recall them.

\section{Reference}

Durie, M. (2006). Maori cultural competemcies for health and disability advocates. Health and Disability Advocacy, Nga Kaitautoko, advocacy. hdc.org.nz. 